\title{
Impaired gastric relaxation in patients with achalasia
}

\author{
F Mearin, M Papo, J-R Malagelada
}

\begin{abstract}
Achalasia is considered a primary motility disorder confined to the oesophagus. The lower oesophageal sphincter (LOS) in achalasia is frequently hypertonic and manifests absent or incomplete relaxation in response to deglution. On the other hand, the LOS and the proximal stomach act physiologically as a functional unit whereby relaxation of the LOS during deglution is associated with receptive relaxation of the proximal stomach. Thus, this study investigated the hypothesis that impaired LOS relaxation in patients with achalasia might be associated with impaired relaxation of the proximal stomach. The study consisted of 20 patients with achalasia and 10 healthy controls. Gastric tone variations were quantified using an electronic barostat. Firstly, the study established the basal gastric tone (intragastric volume at the minimal distending pressure $+1 \mathrm{~mm} \mathbf{~ H g}$ ) and gastric compliance (volume/pressure relation) during isobaric distension (increasing stepwise the intragastric pressure from 0 to $20 \mathrm{~mm} \mathrm{Hg}$ up to $600 \mathrm{ml}$ ). Secondly, the gastric tone response to cold stress (hand immersion into ice water for five minutes) or to control stimuli (water at $37^{\circ}$ ) was determined. Basal gastric tone mean (SEM) was similar in achalasia and in healthy controls (125 (9) $\mathrm{ml} v 138(9) \mathrm{ml}$, respectively). Compliance was linear and similar in both groups, which also showed similar gastric extension ratios (58 (7) $\mathrm{ml} / \mathrm{mm}$ Hg $v 57$ (6) $\mathrm{ml} / \mathrm{mm} \mathrm{Hg}$ ). Cold stress induced a gastric relaxatory response that, as a group, was significantly lower in achalasia than in healthy controls (volume: 43 (20) $\mathrm{ml} v 141$ (42) $\mathrm{ml}$; $p<0.05)$. The responses in each group were not uniform, five of the 20 patients with achalasia showed definite (volume $>100 \mathrm{ml}$ ) relaxatory responses whereas four of the 10 healthy controls did not. In conclusion, reflex gastric relaxation is impaired in most patients with achalasia showing that the proximal stomach, and not exclusively the oesophagus, may be affected by the disease.

(Gut 1995; 36: 363-368)
\end{abstract}

Keywords: achalasia, gastric tone, gastric barostat, gastric relaxation, gastric compliance, cold stress.

Correspondence to: Dr F Mearin, Digestive Hospital General Vall d'Hebron 08035 Barcelona, Spain.

Accepted for publication 9 June 1994
Achalasia constitutes a primary motility disorder of the oesophagus. Several reports suggest, however, that the disease may not be strictly confined to the oesophagus as motor abnormalities of the stomach, ${ }^{12}$ small bowel, ${ }^{3}$ gall bladder, ${ }^{2}$ and sphincter of $\mathrm{Oddi}^{4}$ have been described in some patients. Oesophageal motility in achalasia is characterised by aperistalsis of the oesophageal body and by absent or incomplete relaxatory response to deglution of a frequently hypertensive lower oesophageal sphincter (LOS). ${ }^{5}$ Physiologically, the LOS and the proximal stomach behave in many ways as a functional unit. ${ }^{6}$ Thus, we speculated that in achalasia the motor function of the proximal stomach could be disturbed because the pathogenetic mechanisms interfering with neurally mediated LOS relaxation could also affect reflex gastric accommodation. Indeed, accelerated gastric emptying of liquids is common in achalasia ${ }^{12}$ a piece of evidence that would be consistent with impaired adaptability of the gastric fundus. ${ }^{7}$

The specific aims of this study in achalasia were threefold: firstly, to establish the basal tone of the proximal stomach and its compliance during stepwise distension. Secondly, to quantify the reflex relaxation of the stomach in response to an acute somatic stimulus (cold stress). Thirdly, to discover if visceral perception induced by gastric distension is impaired.

\section{Methods}

\section{SUBJECTS}

Twenty patients with the diagnosis of achalasia were included in the study. They were divided into two different groups: 10 symptomatic patients with untreated achalasia and 10 patients in whom forceful endoscopic dilatation had been successfully accomplished within one year before study. All patients had clinical, radiological, endoscopic, and manometric evidence of achalasia. ${ }^{5}$ Untreated patients complained of grade III or IV oesophageal symptoms according to the criteria of Vantrappen and Hellemans ${ }^{8}$; treated patients were free of symptoms or had slight dysphagia (grade I or II). The Table shows clinical features of the achalasia patients.

Ten healthy volunteers (seven men and three women; 22-26 years) without digestive

Clinical features of achalasia patients

\begin{tabular}{lcc}
\hline & $\begin{array}{l}\text { Untreated } \\
(n=10)\end{array}$ & $\begin{array}{l}\text { After forceful } \\
\text { dilatation } \\
(n=10)\end{array}$ \\
\hline $\begin{array}{l}\text { Sex (male/female) } \\
\text { Age (SD) (y) } \\
\text { (range) }\end{array}$ & $6 / 4$ & $5 / 5$ \\
$\begin{array}{c}\text { Evolution time (SD) (months) } \\
\text { (range) }\end{array}$ & $45(11)$ & $\begin{array}{c}(18-63) \\
(47)\end{array}$ \\
\hline
\end{tabular}


symptoms served as control group for the studies of gastric compliance and gastric relaxation in response to cold stress. Another 10 healthy volunteers (five men and five women; 20-26 years) served as controls for the oesophageal manometric data. All participants gave written informed consent before entering the study. The protocol of the investigation had been approved by the Institutional Review Board of the Hospital General Vall d'Hebron.

\section{PROCEDURES}

Patients had three separate studies on two days. On the first day, an oesophageal manometry was performed and, on the second day, gastric compliance and the gastric relaxatory response to cold stress were evaluated. All studies took place after an overnight fast and drugs had been withdrawn for at least 72 hours before the study.

\section{Oesophageal manometry}

Studies were performed in the supine position after oral passage of the manometric tube. Oesophageal intraluminal pressures were measured using a four lumen polyvinyl tube $(0.9 \mathrm{~mm}$ ID) with its orifices spaced at $5 \mathrm{~cm}$ intervals along the distal part of the tube. The lateral opening manometric catheters were radially oriented. They were perfused with distilled water at $0.1 \mathrm{ml} / \mathrm{min}$ with a pneumohydraulic system. Pressure activity was recorded on a paper polygraph. Resting LOS pressure was assessed during two station pull through and LOS relaxation after ten $5 \mathrm{ml}$ water swallows.

\section{Measurement of gastric compliance}

This was accomplished by producing a standardised gastric distension with the barostat and measuring the resulting volume at each pressure level. ${ }^{9}$ In addition we evaluated the perception elicited by gastric distension.

The gastric barostat measures the volume of air within an intragastric bag maintained by an electronic feedback mechanism at a constant preselected pressure level. A dial in the external electronic component of the barostat permits selection of the desired pressure level. A detailed description of the system has been published. ${ }^{1011}$

The procedure was as follows. The bag of the barostat, finely folded, was introduced through the mouth into the stomach. To unfold the intragastric bag, one lumen of the connecting tube was connected to a pressure transducer, and the bag was slowly inflated through the other lumen of the tube with 300 $\mathrm{ml}$ of air. The bag was then completely deflated and connected to the barostat. Pressure and volume inside the intragastric bag were continuously recorded on a paper polygraph (model 1600, MFE, Salem, NH).

Participants were placed in a $30^{\circ}$ recumbent position and were asked to relax comfortably. Using the pressure selection dial of the barostat, intrabag pressure was gradually increased by $2 \mathrm{~mm} \mathrm{Hg}$ stepwise increments every three minutes, starting at $0 \mathrm{~mm} \mathrm{Hg}$ (atmospheric pressure), until the pressure level that first provided an intrabag volume $>600 \mathrm{ml}$, or when the participants reported discomfort (score $=8$ ). Perception of gastric distension was scored at each pressure step using a rating scale graded from 0 to 10 . We specifically measured perception of upper abdominal sensations excluding those of putative oesophageal origin such as dysphagia, chest pain, heartburn or sensation of a throat lump. Before testing, participants were informed of the several possible sensations they could feel and which they were supposed to score. These included upper abdominal pressure, fullness, bloating, and nausea. These symptoms were selected as the more common sensorial responses to gut distension previously determined in our laboratory and incorporated into a standardised questionnaire. ${ }^{12}{ }^{13}$ The quantification of perception was performed by means of a manually activated scale based on the intensity of upper abdominal sensation. Intensity scores were defined as: 0 , absent sensation; 1 and 2, faint sensation; 3 and 4, mild sensation; 5 and 6 , moderate sensation; 7 and 8, uncomfortable sensation; and 9 and 10 , painful sensation (note that stimulation should be interrupted at score 8 ).

\section{Measurement of the gastric relaxatory response}

To test reflex gastric relaxation in achalasia we selected the 'cold stress test' as we have previously shown that in healthy volunteers it induces a profound relaxatory response of the proximal stomach. ${ }^{9}$

The procedure was as follows. The gastric barostat was positioned and connected to the recording system as described above. We first determined the minimal intragastric distending pressure. We raised intragastric pressure by 1 $\mathrm{mm} \mathrm{Hg}$ increments every two minutes using the pressure selection dial of the barostat. The minimal distending pressure was defined as the first pressure level that provided an intrabag volume of $\geqslant 30 \mathrm{ml}$. This pressure level is needed to overcome the intra-abdominal pressure. ${ }^{11}$ Thereafter, we set an intragastric pressure $1 \mathrm{~mm}$ $\mathrm{Hg}$ above the minimal distending pressure to record gastric tone variations (volume changes at constant pressure) during the study.

After allowing 10 minutes for stabilisation, we tested cold stress and sham stress stimuli.

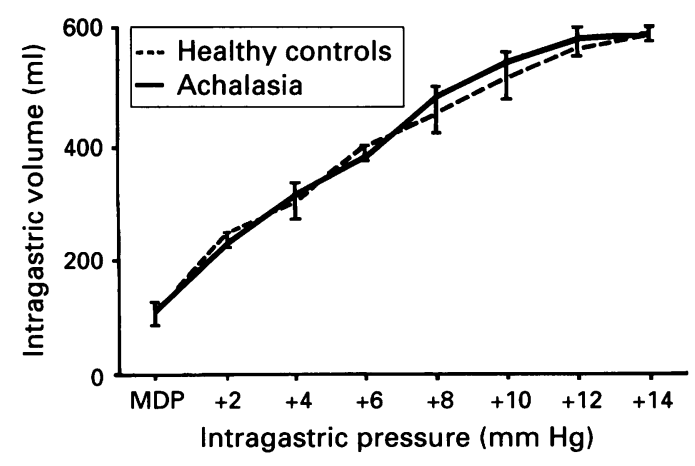

Figure 1: Gastric compliance (volume/pressure relation) in patients with achalasia and healthy controls. $M D P=$ minimal distending pressure. 


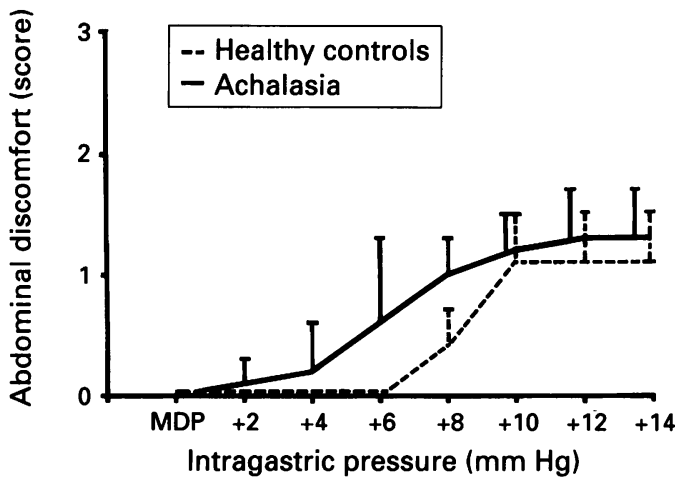

Figure 2: Abdominal discomfort elicited by gastric distension in patients with achalasia and healthy controls. $M D P=$ minimal distending pressure.

Participants were asked to stand up and lean on a high bench in a comfortable position, avoiding positional changes during the tests. After a five minute basal recording period, the stimuli were produced by immersing the nondominant hand into water for five minutes. Four consecutive stimuli were randomly tested: two cold stress stimuli, with the hand immersed in ice water $\left(4^{\circ} \mathrm{C}\right)$, and two sham stress stimuli, with the hand immersed in water at $37^{\circ} \mathrm{C}$. After the cold stimulus, the hand was immersed in water at $40^{\circ} \mathrm{C}$ to produce a quick recovery of hand temperature. The autonomic response was assessed by monitoring brachial blood pressure and pulse rate five minutes before and two minutes after the onset of the stimulus. After the stimulus period, participants were allowed to rest by sitting down for at least 30 minutes until the basal conditions in gastric tone, perception, blood pressure, and pulse rate were fully re-established.

\section{DATA ANALYSIS}

\section{Oesophageal manometry}

Resting LOS pressure was calculated as the mean (SEM) of the eight values obtained during the two pull through of the four lumen catheters; intragastric pressure was used as zero reference. LOS relaxation in response to swallowing was calculated as the mean
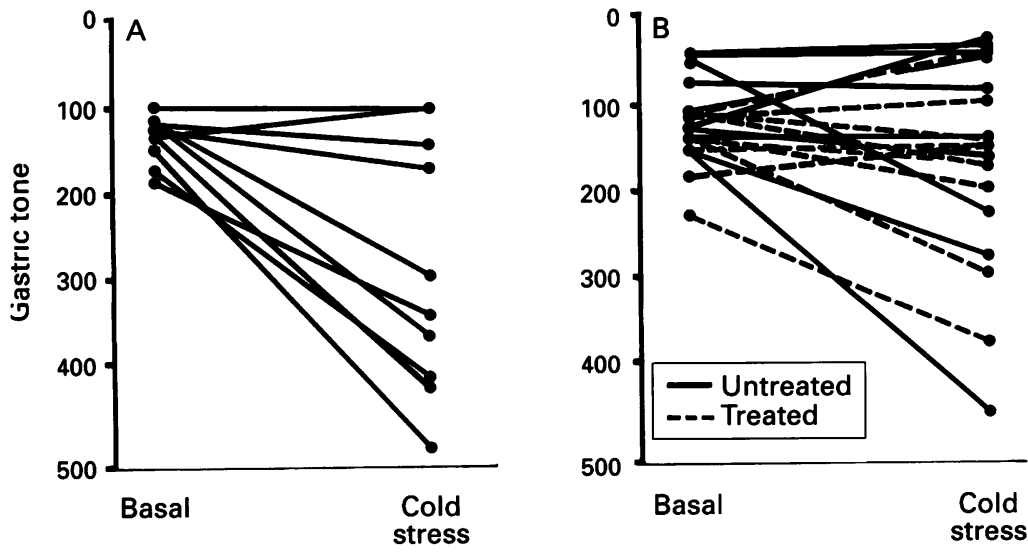

Figure 3: Effect of cold stress on gastric tone. Cold stress induced a spectrum of gastric relaxatory responses in $(A)$ healthy controls $(n=10)$ and $(B)$ achalasia patients $(n=20)$. However, gastric relaxation (decrease in gastric tone) was more frequent in achalasia. percentage from 10 wet swallows, being $0 \%$ the LOS pressure and $100 \%$ the intragastric pressure.

\section{Gastric compliance}

Intrabag volume during each pressure step was averaged. The volume at each pressure level was corrected for air compressibility using Boyle's law $\left(P_{1} V_{1}=P_{2} V_{2}\right)$. In each subject we defined the minimal distending pressure as the first pressure level that provided an intragastric volume of $\geqslant 30 \mathrm{ml}$; this pressure level accounted for intra-abdominal pressure. A compliance curve (volume $v$ pressure) was then constructed starting from the minimal distending pressure level.

\section{Gastric relaxatory response}

In the stress tests (cold stress and sham stress), we measured gastric tone by averaging intragastric volume during the five minute period before the stimulus (basal level) and during the last two minute period of the stimulus (test level). The change in gastric tone produced by the stimulus was calculated as the difference between the test minus the basal levels ( $\Delta$ response).

For statistical analysis we calculated the mean values (SEM) of each parameter measured in the achalasia group and in the healthy control group. Statistical comparisons were performed using Student's $t$ test with paired analysis for intragroup comparisons and unpaired analysis for intergroup comparisons; the non-parametric Mann-Whitney test was used when appropriate. To establish possible correlations we performed linear regression analysis. A p value of $<0.05$ was chosen as the significance value.

\section{Results}

MANOMETRIC EVALUATION OF LOS PRESSURE ACTIVITY

Resting LOS pressure was significantly higher in the untreated achalasia group than in the healthy control group (30 (4) $\mathrm{mm} \mathrm{Hg} v 17$ (1) $\mathrm{mm} \mathrm{Hg}$, respectively, $\mathrm{p}<0.05)$. In five of 10 patients with untreated achalasia, however, values were within the normal range. In patients treated with forceful endoscopic dilatation, resting LOS pressure was similar to that in healthy controls (15 (2) $\mathrm{mm} \mathrm{Hg}$ ).

Mean LOS relaxation in response to wet swallowing was impaired in untreated achalasia patients $(33(6) \%)$ as well as in achalasia patients after forceful dilatation $(23(8) \%)$. A LOS relaxation greater than $75 \%$ was registered in one untreated achalasia patient and in one treated patient.

BASAL GASTRIC TONE AND INTRA-ABDOMINAL PRESSURE

The basal gastric tone was similar in achalasia and in healthy controls (125 (9) $\mathrm{ml}$ and 138 (9) $\mathrm{ml}$, respectively). The minimal distending 

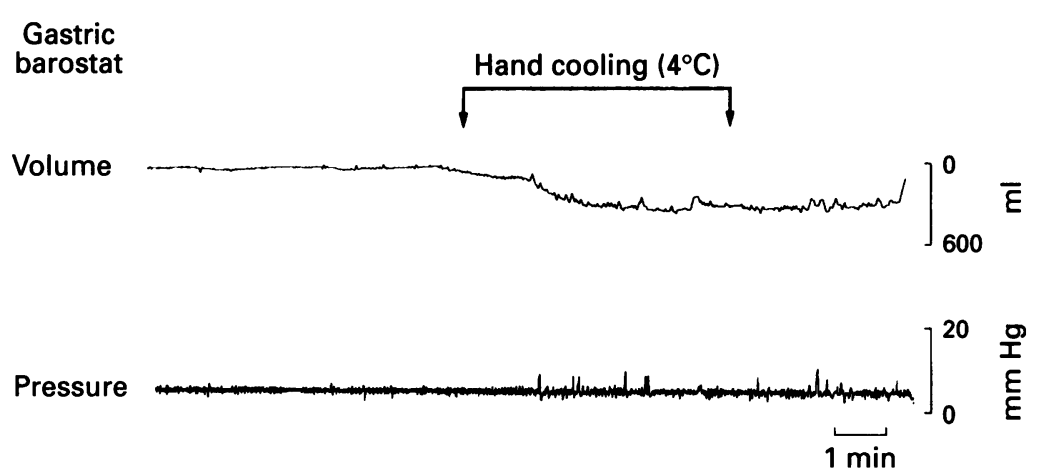

Figure 4: Recording showing gastric relaxation induced by cold stress in a healthy volunteer. pressure, which is equivalent to the intraabdominal pressure, was also similar: $4 \cdot 2(0 \cdot 8)$ $\mathrm{mm} \mathrm{Hg}$ in achalasia patients and $3.7(0.6) \mathrm{mm}$ $\mathrm{Hg}$ in healthy controls. No significant differences were detected between untreated or treated achalasia patients.

\section{GASTRIC COMPLIANCE AND PERCEPTIVE} RESPONSE TO GASTRIC ACCOMMODATION Gastric compliance was similar in patients with achalasia and in healthy controls (Fig 1). Also, there were no significant differences between the gastric compliance of untreated and treated achalasia patients (extension ratios of 57 (8) $\mathrm{ml} / \mathrm{mm} \mathrm{Hg}$ and 60 (9) $\mathrm{ml} / \mathrm{mm} \mathrm{Hg}$, respectively).

The perceptive response to gastric accommodation was also similar in achalasia patients and in healthy controls (Fig 2). At the minimal distending pressure perception of upper abdominal sensations was negligible in both groups. Distending pressures up to $14 \mathrm{~mm} \mathrm{Hg}$ above the minimal distending pressure produced minor abdominal discomfort also in both groups. The perceptive response was unrelated to the presence or absence of oesophageal symptoms because it was similar in untreated and treated achalasia patients.

GASTRIC RELAXATION AND CARDIOVASCULAR AUTONOMIC RESPONSES TO COLD STRESS

Cold stress induced significant gastric relaxation in healthy controls although the magnitude of the response was quite variable (Fig 3). In six of 10 healthy subjects tested, relaxation exceeded $100 \mathrm{ml}$ (Fig 4). In patients with achalasia, mean relaxatory response to cold stress

$\begin{aligned} & \text { Gastric } \\ & \text { barostat }\end{aligned}$
Volume

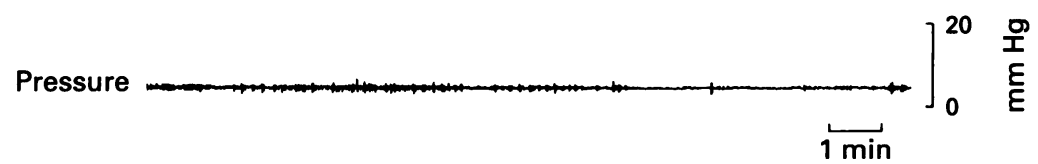

Figure 5: Recording showing absence of gastric relaxation in response to cold stress in a patient with achalasia. did not reach statistical significance and only in five of 20 achalasia patients tested did gastric relaxation exceed $100 \mathrm{ml}$ (Fig 5). Statistical comparison (Mann-Whitney test) of induced gastric relaxation in patients and controls showed a significantly blunted relaxatory response in the achalasia group (Fig 6). The difference in the number of subjects in the control and achalasia groups with a reflex relaxatory response greater than $100 \mathrm{ml}$, however, did not reach statistical significance. During cold stress, brachial blood pressure increased to a similar extent in achalasia patients and healthy controls but the heart rate increase was significantly higher in healthy controls. Sham stimulation did not induce any detectable changes in gastric tone or in the cardiovascular autonomic responses (Fig 6).

No statistically significant relation was found between gastric relaxation and the cardiovascular autonomic response. Moreover, by linear regression analysis, no significant correlation was detected between per cent LOS relaxation during swallowing and the magnitude of gastric relaxation in response to cold stress (Fig 7).

\section{Discussion}

The aetiopathogenesis of achalasia is largely unknown. Ostensibly the disease affects only the oesophagus, which is where the main pathophysiological features of the disease, aperistalsis, and faulty LOS relaxation, have been recognised. However, there are hints that other gastrointestinal functions may be affected. For instance, there have been reports of associated gastric, ${ }^{12}$ intestinal, ${ }^{3}$ gall bladder, ${ }^{2}$ and sphincter of Oddi dysmotility. ${ }^{4}$ Other reports show an impaired gastric secretory response to insulin stimulation ${ }^{14}$ and a blunted plasma pancreatic polypeptide response to sham feeding. ${ }^{15}$ Taken together, these bits of information would be consistent with changed vagal function involving extraoesophageal sites. Additional support for this concept is provided by histological findings of extraoesophageal parasympathetic nerve degeneration in some achalasia patients. ${ }^{16} 17$ There is no consensus, however, on vagal dysfunction in achalasia as other investigators found normal gastric acid secretory response to insulin induced hypoglycaemia ${ }^{18}$ and to sham feeding ${ }^{1}$ as well as no indication of cardiovascular autonomic neuropathy. ${ }^{18}$

In this study we have further advanced knowledge about extraoesophageal neural dysfunction in achalasia by showing that reflex gastric relaxation in response to somatic cold stress is impaired in most patients with achalasia, in the presence of normal gastric compliance and basal tone. We have previously shown that somatic stimulation by acute exposure of the hand to cold does induce relaxation of the proximal stomach in healthy subjects and also in symptomatic dyspeptic patients. ${ }^{9}$ As somatic cold stress tests produce their autonomic activation by the central nervous system, a normal gastric relaxatory response may be considered as evidence of integrity of 

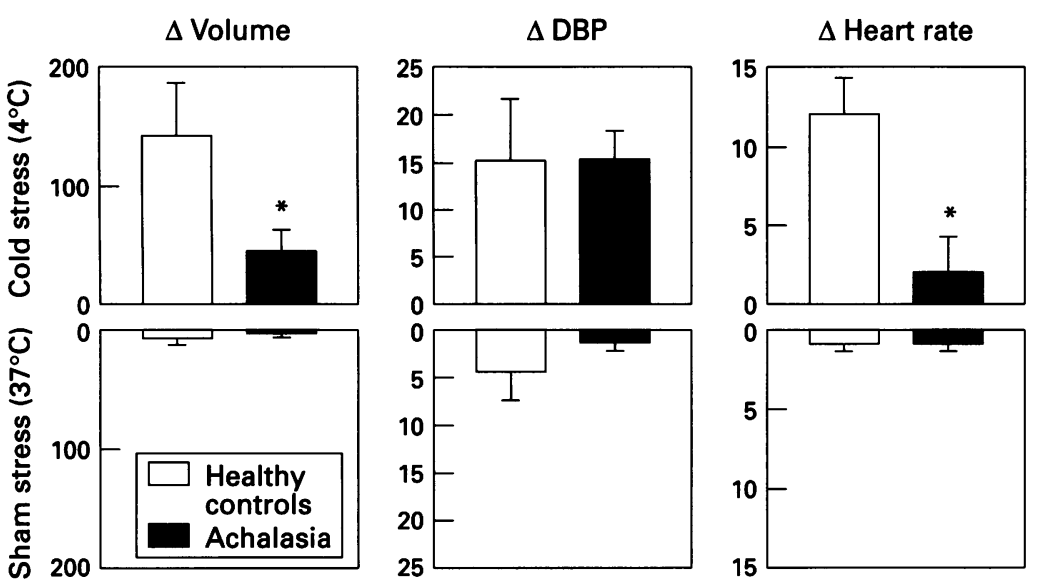

Figure 6: Gastric tone and cardiovascular autonomic response to cold stress and to sham stress in patients with achalasia and healthy controls. $D B P=$ diastolic blood pressure. (Mean (SEM); ${ }^{\star} p<0.05 \mathrm{v}$ healthy controls.)

the neural gastric reflex pathways. Conversely, an impaired relaxatory response, as seen in many of our patients with achalasia, suggests a change in these control pathways to the stomach.

It is apparent from our data, however, that although, as a group, achalasia patients failed to relax their stomach as effectively as the healthy controls, the individual patient responses were somewhat variable with five of 20 achalasia patients showing a good relaxatory response. Such variable response has been equally seen with other features of achalasia, even those regarded as inherent to the oesophageal involvement by the disease. For instance, normal LOS function has been seen in a fraction of achalasia patients ${ }^{19}$ and extraoesophageal abnormalities have been shown only in subgroups of patients with achalasia. In fact, histological studies have shown denervation of ganglion cells of the stomach in about half of achalasia patients. ${ }^{20}$ On the other hand, the effect of cold pain could depend on individual susceptibility and perhaps on the degree of autonomic activation that prevailed at the time of application of the stimulus.

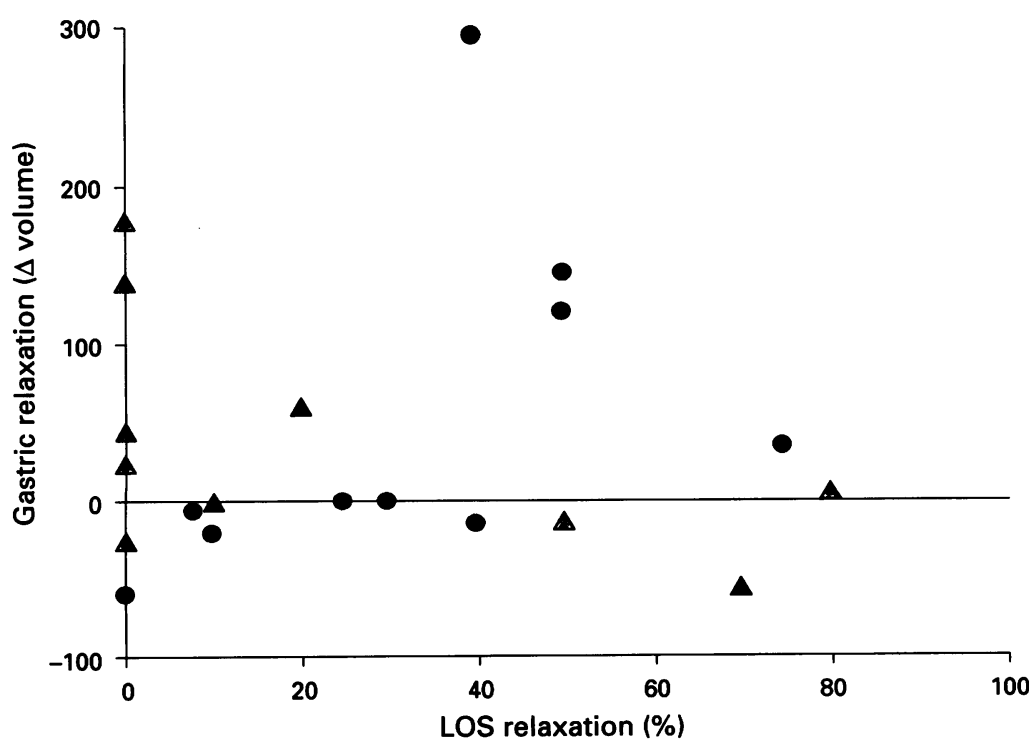

Figure 7: No correlation was found between the per cent LOS relaxation during swallowing and the magnitude of gastric relaxation in response to cold stress in either treated $(\Delta)$ or untreated achalasia patients ( $O)$.
Indeed, the response in healthy subjects is also variable. Moreover, appreciable polymorphism and variability in responses mediated by the autonomic nervous system has been seen in virtually all types of stress studies. ${ }^{21}$ The principal autonomic response to hand immersion in cold water is sympathetic stimulation. ${ }^{22}$ The blood pressure response to cold pain, however, requires not only the integrity of the higher nervous centres but it also depends on the degree of individual response to pain which is variable. ${ }^{23}$

In contrast with the impaired gastric relaxatory response, we saw that basal gastric tone and gastric compliance were normal in patients with achalasia. Basal gastric tone in the fasted state is maintained by an extrinsic cholinergic input, which is vagally mediated. ${ }^{24}$ Therefore, there is no indication of such mechanism being changed in achalasia and our findings are in accordance with other data suggesting that postganglionic cholinergic innervation of the LOS in achalasia patients is normal or minimally impaired. ${ }^{25}$ Nevertheless, chronic vagotomy may be followed by adaptative changes. ${ }^{26}$

A plausible explanation for the impaired gastric relaxatory response seen in achalasia would be a defect in the non-adrenergic-noncholinergic (NANC) inhibitory control of the stomach. This hypothetical pathogenetic mechanism would be comparable with that now most accepted for explaining abnormal LOS relaxation. Vasoactive intestinal polypeptide and nitric oxide, the two important NANC mediators in the LOS, ${ }^{27} 28$ are active inhibitors of proximal gastric tone. ${ }^{29} 30$ Although the presence of these two transmitters in the stomach of achalasia patients has not been determined, lack of vasoactive intestinal polypeptide in myenteric LOS nerves has been previously reported ${ }^{31}$ and the absence of nitric oxide synthase in LOS tissue has been recently described by us. ${ }^{32}$ Although our results suggest that the LOS and the proximal stomach in achalasia could share some pathogenetic mechanisms we could not establish a correlation between per cent relaxation of the LOS and the magnitude of gastric relaxation. There are several possible explanations. Firstly, the relaxatory responses were evaluated in response to different stimuli, swallowing for the LOS, and cold stress for the gastric fundus. Secondly, neuromuscular abnormalities in the oesophagus and in the stomach of patients with achalasia may not be evenly distributed. ${ }^{20}$ Finally, different pathogenic mechanisms might contribute to disturbed LOS and gastric relaxations.

The perceptive response to gastric distension was normal in achalasia showing that the afferent sensorial pathway was not affected by the disease. Visceral nociception seems to be relayed to higher centres by sympathetic nerves, ${ }^{33}$ but the precise pathway is unknown.

In conclusion, we have shown that many patients with achalasia have an impaired gastric relaxatory reflex in response to somatic cold stress. The significance of this finding is that it provides evidence of changed neural regulation 
of gut motility at an extraoesophageal site. Its specific clinical significance remains to be established. Learning more about abnormal regulation of gut motility in achalasia should take us closer to understanding the pathogenetic factors participating in this disease, once considered exclusively an oesophageal disorder and now becoming more clearly a diffuse gut disturbance.

1 Eckardt VF, Krause J, Bolle D. Gastrointestinal transit and gastric acid secretion in patients with achalasia. $\mathrm{Dig}$ Dis $\mathrm{Sci}$ 1989; 34: 665-71.

2 Annese V, Caruso N, Accadia L, Gabrielli A, Modoni S, Frusciante V, et al. Gallbladder function and gastric liquid emptying in achalasia. Dig Dis Sci 1991; 36: 1116-20.

3 Erckenbrecht JF, Berges W, Wienbeck M. Interdigestive dunndarrmmotilitat bei

Gastroenterol 1983; 21: 429 .
Hagenmüller F, Classen M. Motility of Oddi's sphincter in Parkinson's disease, progressive systemic sclerosis and achalasia. Endoscopy 1988; 20: 189-92.

5 Vantrappen G, Hellemans J. Achalasia. In: Vantrappen G, Hellemans J, eds. Diseases of the esophagus. Berlin: Springer-Verlag, 1975: 287-354.

6 Cannon W, Lieb C. The receptive relaxation of the stomach. Am f Physiol 1911; 29: 267-73.

7 Kelly KA. Gastric emptying of liquids and solids: roles of proximal and distal stomach. Am f Physiol 1980; 239: proxima

8 Vantrappen G, Hellemans J. Treatment of achalasia and related motor disorders. Gastroenterology 1980; 79: 144-54.

9 Mearin F, Cucala M, Azpiroz F, Malagelada J-R. The origin of symptoms on the brain-gut axis in functional dyspepsia. Gastroenterology 1991; 101: 999-1006.

10 Azpiroz F, Malagelada J-R. Physiologic variations in canine gastric tone measured by an electronic barostat. $A m \mathcal{F}$ Physiol 1985; 248: G229-37.

11 Azpiroz F, Malagelada J-R. Gastric tone measured by an electronic barostat in health and postsurgical gastroparesis. Gastroenterology 1987; 92: 934-43.

12 Azpiroz F, Malagelada J-R. Isobaric intestinal distension in humans; sensorial relay and reflex gastric relaxation. $\operatorname{Am} \mathcal{f}$ Physiol 1990; 258: G202-7.

13 Azpiroz F, Malagelada J-R. Perception and reflex relaxation of the stomach in response to gut distension. Gastroenterology 1990; 98: 1193-8.

14 Woolom GL, Maher FT, Ellis FR. Vagal nerve function in achalasia of the esophagus. Surg Forum 1967; 18: $362-5$.

15 Dooley CP, Taylor IL, Valenzuela JE. Impaired acid secretion and pancreatic polypeptide release in some patients tion and pancreatic polypeptide release in some pat

16 Cassella RR, Ellis FH, Brown AL. Fine-structure changes in achalasia of the esophagus. Am $\mathcal{F}$ Pathol 1965; 46: 279-88.

17 De la Fuente A, Garcia Calvo M, Cajal SRY, Paya JM, Cuesta G. Alteraciones ultraestructurales del nervio vago en la acalasia del esófago. Rev Esp Enferm Apar Digest 1977; 51: 659-65.

18 Atkinson $M$, Ogilvie AL, Robertson CS, Smart LH. Vagal function in achalasia of the cardia. $Q \mathcal{F M e d ~ 1 9 8 7 ; 6 3 :}$ 297-303.

19 Katz PO, Richter JE, Cowan R, Castell DO. Apparent complete lower esophageal sphincter relaxations in achalasia. Gastroenterology 1986; 90: 978-83.

20 Csendes A, Smok G, Braghetto I, González P, Henriquez A, Csendes $\mathrm{P}$, et al. Histological studies of Auerbach's plexuses of the oesophagus, stomach, jejunum, and colon in patients with achalasia of the oesophagus: correlation with gastric acid secretion, presence of parietal cells and gastric emptying of solids. Gut 1992; 33: 150-4.

21 Lefkowitz RJ. Clinical physiology of adrenergic receptor regulation. Am $\mathcal{F}$ Physiol 1981; 243: E43-7.

22 Lovallo W. The cold pressure test and autonomic function. A review and integration. Psychophysiology 1975; 12: 268-82.

23 Wolff $\mathrm{HH}$. The mechanism and significance of the cold pression response. $Q \mathcal{F} M e d 1951 ; 20: 261-73$

24 Azpiroz F, Malagelada J-R. Importance of vagal input in maintaining gastric tone in the dog. $\mathcal{F}$ Physiol (Lond) 1987; 384: 511-24.

25 Holloway RH, Dodds WJ, Helm JF, Hogan WJ, Dent J, Arndorfer RC. Integrity of cholinergic innervation to the lower esophageal sphincter in achalasia. Gastroenterology 1986; 90: 924-9.

26 Azpiroz F. Control of gastric tone. In: Galmiche J-P, Jian R, Mignon M, Ruszniewski $\mathrm{Ph}$, eds. Non-ulcer dyspepsia: pathophysiological and therapeutic approaches. Paris: John Libbey, 1991: 47-58.

27 Goyal RK, Rattan S, Said SI. VIP as a possible neurotransmitter of non-cholinergic non-adrenergic inhibitory neurons. Nature 1980; 288: 378-80.

28 Tottrup A, Suane D, Forman A. Nitric oxide mediating NANC inhibition in opossum lower esophageal sphincter. Am f Physiol 1991; 260: G385-9.

29 Grider JR, Cable MB, Said SI, Makhlouf GM. Vasoactive intestinal peptide as a neural mediator of gastric relaxintestinal peptide as a neural mediator

30 Desai KM, Sessa WC, Vane JR. Involvement of nitric oxide in the reflex relaxation of the stomach to accommodate in the reflex relaxation of the stomach
food or fluid. Nature $1991 ; 351: 477-9$.

31 Aggestrup S, Uddman R, Sundler F, Fhrenkrug J, Hakanson $\mathrm{R}$, Sorensen HR, et al. Lack of vasoactive intestinal polypeptide nerves in esophageal achalasia. Gastroenterology 1983; 84: 924-7.

32 Mearin F, Mourelle M, Guarner F, Salas A, RiverosMoreno V, Moncada S, et al. Patients with achalasia lack nitric oxide synthase in the gastroesophageal junction. Eur f Clin Invest 1993; 23: 724-8.

33 Cervero F, Tattersall JEH. Somatic and visceral sensory integration in the thoracic spinal cord. In: Cervero $F$, integration in the thoracic spinal cord. In: Cervero F, Morrison JFG, eds. Visceral sensation: progress
research. New York: Elsevier, 1986: 189-205. 